\title{
Onde estão as meninas soldados? Gênero e conflito armado na Colômbia*
}

\author{
Patrícia Nabuco Martuscelli**
}

\section{Resumo}

Este trabalho discute o conceito de vítima e sua aplicação no estudo de crianças soldados, a partir de uma discussão global sobre o emprego de meninas soldados em conflitos armados, visto que esse grupo é duplamente invisibilizado nas categorias de mulheres e crianças. O referencial teórico adotado é a discussão sobre vítimas e infância. São utilizados relatórios de organizações internacionais, organizações de direitos humanos $e$ fontes secundárias de pesquisas etnográficas com crianças soldados em países africanos e asiáticos. Para ilustrar essa discussão, apresentase uma breve discussão sobre o conflito colombiano com o uso de relatórios de organizações de direitos humanos e especialistas que entrevistaram crianças soldado no país. Na Colômbia, o alistamento voluntário de meninas é um modo de empoderamento e fuga de situações de violência, mas violência $e$ discriminação acompanham-nas durante o período junto ao grupo armado e em sua reinserção na sociedade. Sendo assim, se por um lado elas devem ter seus status de vítimas reconhecidos, suas vozes e experiências devem ser consideradas em todo o processo para garantir a elas reintegração e direitos. Ademais, visões tradicionais de vítima não conseguem perceber essas estratégias de resistência e empoderamento.

Palauras-chave: Meninas Soldados, Vítimas, Colômbia, Conflito Armado Interno.

* Recebido em 27 de janeiro de 2017, aceito em 21 de novembro de 2018. Este trabalho foi realizado com apoio da Coordenação de Aperfeiçoamento de Pessoal de Nível Superior - Brasil (CAPES) - Código de Financiamento 001.

** Doutoranda em Ciência Política pela Universidade de São Paulo, São Paulo, SP, Brasil. patnabuco@usp.br / http://orcid.org/0000-0003-2611-2513 


\author{
Where are The Girl Soldiers? \\ Gender and Armed Conflict in Colombia
}

\begin{abstract}
This article discusses the concept of victim and its application in the study of child soldiers, considering a global discussion on the employment of girl soldiers in armed conflicts, since this group has a dual invisibility in the categories of women and children. The theoretical approach of this work is the discussion on victims and childhood. To discuss the application of the concept of victim to the situation of child soldiers, I use reports from international organizations, human rights organizations and secondary sources of ethnographic research with child soldiers in African and Asian countries. To illustrate the issue, a brief discussion is presented of the Colombian conflict using reports from human rights organizations and specialists who have interviewed child soldiers in the country. In Colombia, the voluntary enlistment of girls is a form of empowerment and escape from situations of violence, but violence and discrimination accompany them during their period with the armed group and their reintegration into the Colombian society. Thus, although they must have their status as victims recognized, their voices and experiences must be considered throughout the process to ensure their reintegration and rights. In addition, traditional views of victims fail to recognize their strategies of resistance and empowerment.
\end{abstract}

Keywords: Girl Soldiers, Victims, Colombia, Internal Armed Conflict. 


\section{Introdução}

Em dezembro de 2016, o Tribunal Penal Internacional (TPI), corte internacional criada em 2002, responsável por julgar pessoas que cometem crimes de guerra, crimes contra a humanidade, de genocídio e de agressão, iniciou o julgamento de Dominic Ongwen, um homem de mais de 35 anos. Dominic Ongwen é um dos líderes da milícia Ugandense Lord's Resistance Army (LRA) que perpetrou atrocidades tais como gravidez forçada, estupros, massacres e recrutamento e uso de crianças ${ }^{1}$ soldados. Acontece que o indiciado negou as 70 acusações (dentre elas tortura, escravidão sexual, casamento e gravidez forçados e recrutamento e uso de crianças soldado), afirmando que, por ser uma ex-criança soldado sequestrada pelo LRA aos 10 anos, ele também seria uma vítima dessas atrocidades e não um perpetrador (Burke, 2016).

$\mathrm{Na}$ Colômbia, está sendo implementado o Acordo de Paz com uma das principais guerrilhas para terminar um conflito que dura mais de 50 anos e que emprega cerca de 18 mil crianças soldados, segundo estatística da especialista Springer (2012) que entrevistou ex-menores e recrutadores. Discute-se como ficará a situação das crianças, meninos e meninas, que participaram do conflito em diversas capacidades. Principalmente porque grandes líderes dos principais grupos armados que atuam no país passaram a integrar esses grupos antes ainda de seus 18 anos: cerca de 52,3\% dos combatentes adultos da guerrilha Ejército de Liberación Nacional (ELN); 50,15\% dos adultos membros das Fuerzas Armadas Revolucionarias de Colombia - Ejército del Pueblo (FARC-EP) e 38,12\% dos adultos parte do grupo paramilitar Autodefensas Unidas de Colombia (AUC), que passou por um processo de desmobilização de fachada tendo se reorganizado em

\footnotetext{
1 Neste trabalho, o termo crianças deve ser entendido de acordo com o artigo $1^{\circ}$ da Convenção das Nações Unidas sobre os Direitos da Criança (1989), ou seja, qualquer pessoa menor de 18 anos. Ainda que essa definição não leve em consideração particularidades culturais, todos os países do mundo, com exceção dos Estados Unidos da América, ratificaram dito tratado, de modo que é possível entender que existiria um consenso em torno dessa definição.
} 
diversos grupos armados conhecidos como grupos pósdesmobilização ou bandas criminales (BACRIM) (Springer, 2012). Por meio da sentença C-069/16, emitida em fevereiro de 2016, a Corte Constitucional da Colômbia decidiu que todas as crianças soldados que se desvinculem até atingirem 18 anos, independentemente do grupo do qual elas faziam parte, devem ser consideradas como vítimas do conflito armado interno $e$ devem receber assistência, compensação e reintegração local conforme a Lei n. 1448 de 2011, conhecida como Lei de Vítimas e Restituição de Terra. Essa lei classifica vítimas, de acordo com seu artigo $3^{\circ}$, como as pessoas que individual ou coletivamente tenham sofrido um dano por fatos ocorridos a partir de $1^{\circ}$ de janeiro de 1985, como consequência de infrações ao direito internacional humanitário ou de violações graves e manifestas às normas internacionais de direitos humanos, que tenham ocorrido por ocasião do conflito armado interno.

Esses novos acontecimentos têm chamado atenção para essa discussão sobre como classificar crianças soldado internacionalmente, principalmente meninas que estão inseridas em marcadores sociais de raça, gênero e idade. O que significa classificar uma criança soldado como vítima? Quais são as implicações intrínsecas nesse conceito e como elas se relacionam com o contexto por trás do recrutamento de menores de 18 anos em guerras? Ademais, como isso se aplica no caso das meninas soldados - inseridas em categorias específicas de idade e gênero? Este artigo, utilizando como referencial teórico o arcabouço conceitual de uma discussão sobre vítimas e infância, apresenta, com o uso de relatórios de organizações internacionais como a Organização das Nações Unidas (principalmente o Conselho de Segurança) e de direitos humanos como a Human Rights Watch $e$ pesquisas acadêmicas etnográficas e sociológicas, uma discussão global sobre o envolvimento de meninas em conflitos armados. Para ilustrar essa discussão, são apresentados alguns dados sobre a situação das meninas soldados colombianas à luz de algumas análises sociológicas/antropológicas sobre os usos e implicações da noção de vítima no mundo contemporâneo. 
O caso colombiano é útil para ilustrar essa discussão dado o momento pós-negociação de um acordo de paz com a guerrilha FARC-EP $e$ a definição de vítimas da Corte Constitucional Colombiana. A situação da Colômbia é apresentada com dados da organização internacional de direitos humanos Human Rights Watch e com a pesquisa de Natalia Springer. Segundo dados da pesquisa de Springer (2012), cerca de $81 \%$ dos menores desvinculados do conflito consideram seu recrutamento voluntário, ou seja, essas crianças não seriam "vítimas de verdade", conforme discutido por Lins (2014).

A definição formal de crianças soldados, segundo os Princípios da Cidade do $\mathrm{Cabo}^{2}$ (1997), envolve o emprego de qualquer menor de 18 anos em atividades diretas ou indiretas em um conflito armado, o que inclui tanto crianças combatentes quanto aquelas que são utilizadas para atividades de inteligência $e$ apoio como mensageiras, cozinheiras e carregadoras. Apesar de este documento internacional considerar o envolvimento de menores para serviços sexuais e casamento forçado, a definição de criança soldado nele contida não é um conceito neutro em termos de gênero, nem leva em consideração os diferentes estágios de desenvolvimento das crianças ou as diferentes experiências da pluralidade de situações/sujeitos envolvidos no tema da criança soldado. Muitas meninas são combatentes $e$ desenvolvem diversas atividades na vida militar, mas são excluídas de pesquisas sobre crianças soldados e programas de desarmamento, desmobilização e reintegração ${ }^{3}$ (DDR) por

\footnotetext{
${ }^{2}$ Apesar de não ser um tratado internacional de cumprimento obrigatório para os Estados, os Princípios da Cidade do Cabo são um documento internacionalmente aceito cuja definição de criança soldado é utilizada $e$ reconhecida por organizações internacionais, Estados e organizações da sociedade civil.

${ }^{3}$ Para atingir a paz, é esperado que os combatentes se desarmem, deixem os grupos ou forças armadas dos quais fazem parte (se desmobilizem) e se reintegrem à vida como civis. Para isso, negociações de paz pressupõem programas de DDR para que esses combatentes possam deixar de vez as armas $e$ reconstruírem suas vidas. Programas de DDR também podem acontecer em meio ao conflito, especialmente porque organizações internacionais como a ONU
} 
discriminações de gênero existentes em suas sociedades e na própria definição de crianças soldados que não leva em consideração questões de gênero. Essa percepção é extremamente necessária em nossa análise do conceito de vítima porque meninas seriam consideradas duplamente vitimizadas por razões de gênero $e$ idade. As experiências de meninas indígenas $e$ afrodescendentes são ainda mais inviabilizadas por pertencerem a determinadas categorias de etnia e raça que não são devidamente contempladas em estudos e relatórios oficiais.

Este trabalho foi organizado em quatro partes além dessa introdução, visando atender a análise proposta. Na primeira seção, apresenta-se uma discussão sobre o conceito de vítima $e$ como ele se relaciona com a situação das crianças soldados e mais especificamente das meninas. Em seguida, são apresentados alguns fatos sobre o uso de meninas soldados no mundo de modo geral. A seção seguinte utiliza a situação das meninas soldados na Colômbia e as lógicas por trás dessa situação para ilustrar a discussão apresentada na seção anterior. Nas considerações finais, retoma-se a discussão sobre como classificar as meninas soldados colombianas como vítimas contribui para a garantia de seus direitos, mas ao mesmo tempo impede o reconhecimento de estratégias de empoderamento e resistência empregadas por elas.

\section{Vítimas e crianças soldados}

A primeira dificuldade em lidar com o tema de crianças soldados é que esse conceito deturpa a ideia socialmente

tentam retirar crianças dessas situações. Eles podem ser organizados pelos Estados com apoio de organizações internacionais ou por organizações internacionais. Na Colômbia, a organização governamental Instituto Colombiano de Bienestar Familiar (ICBF), em parceria com o Fundo das Nações Unidas para a Infância (UNICEF) e a Organização Internacional das Migrações (OIM), é responsável pelos programas de DDR desde 1999. O programa oferece acolhimento, educação, cuidados médicos e psicológicos para que a criança possa retornar para suas famílias e comunidades e retomar sua vida. Segundo informações da USAID e OIM (2017), de 1999 até setembro de 2017, foram desmobilizadas 6394 crianças, $29 \%$ delas do sexo feminino. 
construída que se tem de criança como inocência e lugar de proteção, vulnerabilidade e passividade. Boyden (2003) defende que as crianças que lutam entram em uma condição social que desvirtua o status aceito de infância. Há uma simbolização sentimental das crianças como a esperança abstrata comum da humanidade para resolver, no futuro, problemas sociais criados pelos adultos (Dubinsky, 2012). Criança soldado, como categoria social, não desafia apenas o conforto baseado na natureza da infância, mas também os entendimentos tradicionais sobre guerra e violência (Monforte, 2007). Crianças combatentes são um dilema para a sociedade adulta porque o ato de participar de um conflito não condiz com a categoria de criança. Como quem guerreia é o adulto, menores envolvidos em conflitos armados são muitas vezes excluídos dos benefícios e da proteção associados ao conceito tradicional de criança (Boyden, 2003). Por outro lado, o fato de participarem de uma guerra não lhes garante a plena entrada no mundo adulto, nem seu reconhecimento como participantes ativos da vida de suas sociedades. Percebe-se que uma criança inserida na guerra atuando com um grupo armado mescla a divisão entre civil e combatente e inverte as visões tradicionais de infância como local de proteção e cuidado. Sendo assim, faz-se necessário entender como se classifica o conceito de vítima para pensar se crianças soldados deveriam ser consideradas como vítimas ou como perpetradoras de atrocidades.

Para Fassin e Rechtman (2009), um grupo se identifica como vítima ao reconhecer uma experiência comum de violência. De modo que o trauma seria tanto o produto de uma experiência de desumanidade quanto a prova de humanidade daqueles que sobreviveram a isso. A categoria de vítima ganha legitimidade quando o trauma aparece para atestar a verdade de sua versão $e$ essa mudança ocorre tanto no campo científico com a definição de trauma quanto no campo moral que passa a reconhecer a vítima. Para Sarti $(2011: 54,56)$, "a construção da pessoa como vítima no mundo contemporâneo é pensada como uma forma de conferir reconhecimento social ao sofrimento, circunscrevendo-o $e$ dando-lhe inteligibilidade", ou seja, dá-se "inteligibilidade ao 
sofrimento de segmentos sociais específicos, em contextos históricos precisos, que se produzem ou são produzidos como tal, conferindo legitimidade moral à suas reivindicações". Nessa lógica, crianças soldados deveriam ser consideradas como vítimas porque são de um segmento social específico que passou por experiências de sofrimento oriundas do fato de que essas crianças foram forçadas de alguma maneira a entrar em um conflito armado do qual, em primeiro lugar, elas deveriam ser protegidas pelos seus Estados. Sendo assim, classificar crianças soldados como vítimas significa reconhecer seus direitos de compensação, necessidade de proteção $e$ reintegração à sociedade $e$ não culpabilidade pelas atrocidades cometidas, ou seja, o trauma e a categoria de vítimas são ferramentas usadas para demandar justiça para esse grupo. Isso vai ao encontro do que Fassin e Rechtman (2009) mostram sobre como a criação da categoria do trauma levou ao reconhecimento dos direitos das vítimas à compensação, possibilitando que seu sofrimento fosse reconhecido como tal. Ao mesmo tempo, o fato de crianças soldados terem cometido atrocidades não impediria que elas fossem classificadas como traumatizadas porque, como argumentam Fassin e Rechtman (2009), a mesma classificação psicológica é aplicada à pessoa que sofre a violência, à pessoa que comete a violência $e$ à pessoa que presencia a violência. Nesse caso, crianças soldados seriam três vezes traumatizadas por sofrerem violências, serem forçadas $e$ socializadas para cometerem violências $e$ presenciarem colegas $e$ civis sofrendo diferentes tipos de violência.

Classificar uma pessoa como vítima lhe garante uma capacidade de voz dentro do léxico criado com a categoria de trauma em que essa vítima pode apresentar sua versão dos fatos. Ao mesmo tempo, a credibilidade de sua narrativa dependerá do reconhecimento de sua condição como vítima e isso depende de como a sociedade concebe a visão de vítima. Ou seja, como defende Sarti (2011:58),

a análise da construção da vítima supõe necessariamente o agressor e o contexto da violência, que permitem entender 
a lógica a partir da qual ela se manifesta e é qualificada como tal. Ser vítima não corresponde a um lugar fixo.

Na definição de vítimas da Corte Constitucional colombiana, a ideia de trauma está relacionada ao conceito de dano sem necessariamente ser necessário identificar o agressor. Isso é decorrente do entendimento de que a existência de um conflito armado por si só levaria a danos individuais ou coletivos. No caso do tema das crianças soldados, é muito difícil identificar e punir o recrutador. Ademais, as crianças também se tornam agressoras $e$ isso torna questionável sua condição como vítimas.

Nesse sentido, é interessante a discussão feita por Lins (2014), em sua dissertação sobre a Lei Maria da Penha e sua aplicação em duas delegacias da mulher em São Paulo. A autora analisa a ideia de "vítima de verdade" no caso de mulheres que sofreram violência doméstica. Ainda que não consiga definir exatamente como as policiais e escrivãs conceituariam uma "vítima de verdade" (exatamente por esse conceito ser fluido e estar conectado com o contexto), é possível depreender do esforço analítico da pesquisadora que uma vítima de verdade estaria relacionada com as características de vulnerabilidade, dependência, passividade e fragilidade das mulheres que denunciavam a violência doméstica. Ou seja, "uma pessoa verdadeiramente vitimizada precisaria estar em uma situação de inferioridade, dependência e impotência em relação ao seu algoz e à violência sofrida" (Lins, 2014:119). No caso das crianças soldados, quando elas são sequestradas ou forçadas a se vincularem a um grupo armado percebe-se claramente essa questão da vulnerabilidade, passividade, dependência $e$ fragilidade da criança frente ao conflito armado, ou seja, elas são "vítimas de verdade". Contudo, há crianças que consideram sua entrada no grupo armado como tendo sido voluntária. Nessa situação, torna-se ainda mais frágil a possibilidade de que as comunidades locais percebam essas crianças como "vítimas de verdade". 
A realidade para muitas crianças soldados é o recrutamento forçado por meio de ameaças ou abduções, sendo que, ao se recusarem a se juntar a uma unidade militar ou a obedecerem a ordens, poderão ser mortas. No entanto, uma parte das crianças soldados se envolve em conflitos armados de maneira voluntária, ou seja, sem ser sequestrada ou fisicamente forçada a se juntar a um grupo armado (Boyden, 2003). Assim, se uma criança se voluntariou, não há razões lógicas para esperar que ela deseje sair do grupo armado ou não retornar a ele em caso de ser desmobilizada, por isso faz-se necessário identificar as causas desse "alistamento voluntário" para poder abordá-lo (Brett, 2003a).

Em sua análise sobre a Palestina, Fassin e Rechtman (2009) reconhecem que os palestinos tendem a se classificarem como combatentes e não vítimas. Essa mesma visão pode aparecer em crianças que se voluntariam por uma causa. Seriam esses dois conceitos tão incompatíveis? Acredita-se que a sociedade faça essa distinção quando lhe convém, ou seja, em um conflito armado, as forças inimigas tendem a ser vistas como combatentes $e$ não vítimas, contudo, os soldados nacionais ou aliados são percebidos por suas comunidades locais como combatentes e vítimas. Ao se tratar de crianças que cometeram atrocidades contra suas próprias comunidades é muito difícil pensar que elas seriam vistas como vítimas indefesas (independentemente do tipo de recrutamento que tiveram) e perdoadas por essas sociedades, principalmente as meninas que foram ativas sexualmente $e$ violadas pelo inimigo porque, muitas vezes, elas retornam com os filhos desse inimigo.

Em uma situação de conflito armado, crianças podem se ver forçadas pelo contexto em que vivem a realizar um cálculo de que a adesão voluntária a grupos armados seria a melhor decisão. Elas consideram nesses cálculos também fatores estruturais (violência, pobreza, ausência do Estado, ausência de proteção familiar). Além disso, deve-se lembrar que, para os recrutadores de crianças, elas se voluntariarem pouparia o trabalho deles, recrutadores, de realizar abduções e rituais macabros para quebrar os laços com a família e a comunidade. Crianças que se voluntariam serão mais 
reticentes a desertar, pois consideram que estão lá por escolha própria - a melhor disponível.

As lógicas que levam a esse recrutamento devem ser compreendidas e consideradas em processos de DDR, porque uma criança que se voluntariou poderá fazê-lo de novo se se encontrar na mesma situação que a da primeira vez, ou seja, suas visões devem ser levadas em conta em processos de desmobilização $e$ reintegração para evitar o re-recrutamento, principalmente em situações em que não há de fato o fim do conflito armado mesmo após a assinatura de um acordo de paz. Esse é um dos riscos da situação na Colômbia em que as FARC-EP se desmobilizaram, mas outros grupos e uma dissidência das FARC-EP continuam ativos $e$ recrutando crianças.

A pobreza seria uma causa direta $e$ indireta para crianças voluntariamente se tornarem soldados (Brett, 2003a). Fome e pobreza podem levar os pais a oferecerem seus filhos para serviços militares ou estimularem que eles se voluntariem como forma de garantir refeições regulares, vestimentas e cuidados médicos (Annan, 2000). A pobreza familiar pode levar as crianças a terem que apoiar financeiramente suas famílias. A falta de oportunidades educacionais $e$ treinamento vocacional pode render a esses menores poucas alternativas de emprego, principalmente em um contexto de conflito armado em que escolas e creches são fechadas (Machel, 1996).

Quando exércitos e grupos armados são percebidos como os únicos "empregadores", essa é a "alternativa" escolhida pelas crianças como última forma de apoiar a si mesmas e a suas famílias. Desse modo, para eliminar o uso de crianças soldados devem-se providenciar alternativas adequadas e oportunidades também para se evitar outros tipos de trabalho infantil (Boyden, 2003). A ausência de perspectivas de emprego formal ou outra atividade econômica rentável faz com que o alistamento se torne a oportunidade de emprego, seja essa formal junto ao exército ou informal como fonte de renda e comida por meio de grupos armados (Brett, 2003a). 
Para menores em situações precárias, sem perspectivas de desenvolvimento pessoal e econômico ou emprego, juntar-se a um grupo armado é uma forma de segurança coletiva e individual (Vautravers, 2009). Onde há uma quebra dos laços familiares e sociais, grupos armados podem ser vistos como os únicos provedores de refúgio e segurança para as crianças. Assim, elas fariam um cálculo racional de que entrar em um grupo armado, que permitirá o acesso a refeições regulares, roupas e cuidados médicos, e segurança por estarem armadas, além de desfrutarem de uma sensação de poder e das supostas regalias da vida militar (Rosen, 2007), é mais vantajoso do que permanecer um civil desprotegido pelo Estado e à mercê da vontade dos grupos armados, principalmente no caso das meninas que são mais propensas a serem violadas sexualmente.

É reconhecido que a destruição ou a dispersão de suas famílias pode levar crianças a se juntarem a grupos armados para seu próprio sustento e sobrevivência. De fato, crianças sozinhas, permanente ou temporariamente, são mais vulneráveis ao recrutamento forçado ou voluntário (Brett, 2003a; Machel, 1996). O Comitê Internacional da Cruz Vermelha admite que a violência da rua, a extrema pobreza e a ausência de estruturas de apoio aumentam a probabilidade de uma criança ser recrutada. Menores sem seus pais por causa de mortes ou deslocamentos também são mais vulneráveis e precisam desenvolver estratégias de sobrevivência. Nessa lógica, juntar-se a um grupo armado pode ser uma maneira de obter um tipo de proteção ou status social (ICRC, 2013).

Alguns menores, principalmente meninas, voluntariam-se para escapar de uma situação familiar opressiva ou da humilhação (bullying) sofrida na escola (Brett, 2003a). De fato, essa causa começa a aparecer recentemente na literatura sobre o assunto, que passa a identificar um número crescente de adolescentes que fogem de um contexto doméstico discriminatório, abusivo, violento e explorador. Em alguns países, como a Colômbia, há uma relação entre meninas que sofrem exploração doméstica, abuso físico e/ou sexual e suas decisões de se juntarem a grupos 
armados (Brett, 2003a; HRW, 2003). Dessa forma, o alistamento voluntário é percebido por essas crianças como uma maneira de empoderamento frente às suas sociedades, visto que, a partir dele, elas serão respeitadas por estarem armadas e não mais permitirão abusos e explorações.

Outras causas para que jovens se voluntariem envolvem busca por aventura, identidade e reconhecimento, o modelo da vida militar (seja esse real ou fictício) ou para servir a uma causa religiosa, étnica ou política (Brett, 2003a). Segundo Annan (2000), crianças podem se identificar com causas sociais, expressões religiosas, autodeterminação, liberação nacional ou busca de liberdade política para se juntarem a um grupo armado. Assim, muitos adolescentes se voluntariam por ideologia, principalmente em contextos nos quais a defesa da família, da comunidade ou da nação é um dever social (Boyden, 2003). Nessas situações, as crianças são consideradas as guardiãs da nação e treinadas para se tornarem os mártires de suas comunidades (Fernando, 2001). Outra justificativa apresentada por crianças para terem se voluntariado foi a vingança por seus parentes e sua comunidade contra injustiças perpetradas contra eles por grupos rivais. Crianças também podem entrar em forças combatentes por causa da existência de culturas masculinizadas que valorizam $\mathrm{o}$ militarismo (Park, 2006).

Muitas crianças soldados se alistam voluntariamente por realizarem o cálculo racional de que eventualmente serão recrutadas de maneira forçada e que ser um voluntário pode trazer benefícios, como a escolha do comandante e das funções enquanto que ser um recrutado de maneira forçada envolva por vezes mais custos. Essa questão se aplica especialmente às meninas que poderão exercer algum tipo de decisão sobre quem servirão sexualmente em detrimento de serem estupradas por batalhões inteiros. Nesse sentido, a decisão de se juntar a um grupo armado pode ser vista quase como uma maneira de proteção em um contexto de violência, conflito e insegurança.

Tudo isso contribui para a discussão de se as crianças deveriam ser tratadas como vítimas ou como perpetradoras de 
atrocidades. Aqueles que defendem que as crianças devem ser punidas pelas atrocidades cometidas reconhecem que essa é uma ação necessária para evitar que os comandantes deleguem a elas as piores tarefas e também para diminuir o número dos alistamentos voluntários. Por outro lado, aqueles que defendem que as crianças são vítimas de um conflito armado afirmam que a culpa de seu recrutamento está na falta de proteção dada pelo Estado e na existência de um conflito armado no qual essas crianças nem deveriam estar envolvidas em primeiro lugar. Sendo assim, os principais responsáveis pelas atrocidades cometidas pelas crianças seriam seus comandantes $e$ recrutadores que as envolveram, de alguma forma, em um conflito do qual elas não deveriam participar. Neste artigo, a discussão é feita na direção desta segunda perspectiva.

Apesar de as razões para as crianças se voluntariarem envolverem desejo por vingança, busca por aventura, diversão, senso de pertencimento e pressão dos pares, a maior parte delas se voluntaria, prioritariamente, para sobreviver. Como sobrevivência não é uma escolha e sim uma necessidade humana, de fato não existe o alistamento voluntário de crianças quando ele ocorre em uma situação de conflito armado. Ainda que alguns desses motivos possam justificar a ideia de alistamento voluntário, essas buscas infantis por poder, aventura, reconhecimento $e$ identidade aconteceriam de outras maneiras em um contexto de paz. Dessa forma, um estado de exceção como o de conflito armado influencia negativamente e distorce as opções das crianças, de modo que não se pode falar claramente de uma escolha voluntária por entrar para uma força ou grupo armado, principalmente considerando o modelo de homem rousseauniano em que se baseia esta análise. Assim, quando se estuda o tema de crianças soldados, conclui-se que há apenas recrutamentos forçados, sejam esses diretos, por meio de ameaças ou abduções, sejam indiretos com questões que coagem a criança a uma escolha que ela talvez não fizesse em uma situação de ausência de conflito. Dessa forma, não há como se falar em alistamento 
voluntário de crianças quando há uma situação de guerra, por não haver alternativas a ela.

Ao mesmo tempo, punir penalmente crianças soldados por seus atos não elimina ou mesmo diminui os fatores socioeconômicos que impactam no seu recrutamento, ou seja, responsabilizar as crianças soldados pouca diferença fará, tanto no cálculo dos recrutadores, quanto nos das crianças na hora de decidirem se alistar. Responsabilizar penalmente as crianças soldados não levará à diminuição do uso delas nos conflitos e do recrutamento por grupos armados, pelo contrário, tais forças tenderão ainda mais a negar essa prática $e$ as crianças se negarão a passar por processos formais de DDR, que levariam à sua reinserção em suas comunidades, por temerem serem responsabilizadas. Corrobora essa ideia o fato de que a diminuição da maioridade penal em diversos países não levou a quedas significativas nas taxas de criminalidade. Além disso, seria inocente esperar que os tribunais nacionais $e$ internacionais conseguissem julgar todas as crianças soldados se esses não são capazes nem de processar todos aqueles que cometem o crime de guerra de recrutar menores.

Penalizar crianças soldados é condená-las duplamente. Primeiro, essas crianças são condenadas a serem envolvidas em conflitos armados que violam todos os seus direitos; $e$, em seguida, elas teriam que responder por escolhas que não foram feitas em situações normais, nas quais várias alternativas estavam disponíveis. As crianças não escolhem livremente se tornar soldados, mas são forçadas a tomar essa decisão por fatores socioeconômicos que estão fora de seu controle e que não são considerados por tribunais internacionais, nem resolvidos judicialmente. A decisão de se juntar a um grupo armado em um contexto de guerra civil, crise do Estado, insegurança, criminalidade e impunidade é uma resposta a uma variedade de pressões econômicas, sociais, políticas e culturais (Machel, 1996). O grau de real liberdade de decisão no caso de alistamento varia de caso a caso (Brett, 2003a), contudo, ela não é completamente livre. Adolescentes, por exemplo, voluntariam-se para grupos armados 
acreditando que poderão sair quando quiserem, o que não acontece. Algumas vezes, eles são deliberadamente enganados sobre isso (Brett, 2003a), o que impacta o grau de liberdade de suas decisões e altera o cálculo de custos e benefícios de se alistar ou não.

O Comitê Internacional da Cruz Vermelha e a Coalizão para Acabar com o Uso de Crianças Soldados defendem que crianças que foram recrutadas ilicitamente e que são acusadas de terem cometidos crimes domésticos e internacionais durante o conflito devem ser vistas primeiramente como vítimas e não apenas perpetradoras (ICRC, 2013). Essa mesma visão está presente no documento da UNICEF sobre os Princípios e Diretrizes de Paris de 2007. Para a Cruz Vermelha, qualquer sentença dada para esses menores deve ter o propósito de reabilitá-los e reinseri-los em suas famílias e comunidades, para evitar, inclusive, um rerecrutamento. Há o temor de que, se as crianças soldados não forem responsabilizadas por suas ações, elas não responderão pelas atrocidades que cometeram e crescerão como adultos que não lidam com as consequências de suas ações, como se tivessem sido desensibilizadas de atos violentos por meio do seu tempo em combate (Nwoko, 2011). Por outro lado, crianças não possuem a experiência de mundo e a razoabilidade para entenderem a gravidade das ações cometidas (Boyden, 2003), principalmente quando elas são forçadas a isso por comandantes mais poderosos que podem matá-las e torturá-las a qualquer momento.

O entendimento do Alto Comissariado das Nações Unidas para Refugiados (ACNUR) e da maioria dos países sobre a exclusão desses menores da condição de refúgio corrobora os argumentos contra a criminalização de crianças soldados. O Artigo 1F da Convenção de Genebra sobre o Status de Refugiado (1951) afirma que aqueles que cometeram crimes de guerra, crimes contra a humanidade e crimes contra a paz não podem receber a proteção internacional da instituição do refúgio. Entretanto, crianças combatentes que estão fugindo dos conflitos devem ser reconhecidas como refugiadas de acordo com o Manual de Determinação do Status de Refugiados, organizado pelo ACNUR 
(UNHCR, 2011). Dessa forma, o entendimento majoritário sobre o assunto (que também é observado pela decisão do TPI de não processar menores de 18 anos) é que o envolvimento de crianças em conflitos armados acontece por questões alheias à sua vontade, de modo que não há responsabilização sem o fator de intenção (vontade).

Considerando que o alistamento voluntário de fato não existe, é apenas aparente, pois crianças não se voluntariam se um conflito armado que viola todos os seus direitos não estiver em curso, infere-se que crianças soldados são um resultado de uma situação de recrutamento forçado direto ou indireto e que, por isso, não devem ser responsabilizadas por seus atos. Ao mesmo tempo, seria um erro considerar a ausência de possibilidade de agência ou de razão instrumental dessas crianças e tomá-las como meras vítimas. As crianças devem ter consciência de suas ações $e$ lidar com suas culpas, o que deve ser feito em programas de DDR e Comissões da Verdade e não em tribunais nos quais adultos que não participaram do conflito decidem sobre situações extremas que levaram as crianças a se envolverem com forças e grupos armados. Dessa forma, os programas e mecanismos de DDR também devem ser pensados sem culpar essas crianças, mas com o intuito de ensiná-las sobre a gravidade dos atos cometidos $e$ sobre como lidar com seus traumas. Ao mesmo tempo, os recrutadores devem responder penalmente, tanto pelo recrutamento de menores, quanto pelos crimes por eles perpetrados, visto que esses adultos tinham consciência do que estavam fazendo e decidiram delegar as piores atividades para as crianças soldados, fazendo-o, portanto, deliberadamente.

Ainda assim deve-se considerar que a definição de vítima é política. Como lembram Fassin e Rechtman (2009), o processo social de reconhecimento de pessoas como traumatizadas escolhe suas vítimas. Esse reconhecimento do trauma depende de dois elementos: a possibilidade de políticos, trabalhadores humanitários, mídia e especialistas de saúde identificarem certas pessoas como vítimas e a proximidade cultural, social e ontológica entre vítimas e essas pessoas que as identificam. Isso leva à 
avaliação a priori da validade da causa, da falta de sorte ou do sofrimento, avaliação essa que implica um julgamento político $e$ ético. Também são considerados a natureza dos eventos ditos traumáticos, o valor dado para a vida daqueles que sofrem $e$ a necessidade de proteger determinados grupos em detrimento de outros. Por essa lógica, crianças soldados serão consideradas como vítimas quando isso for interessante para o discurso político e humanitário vigente. Nesse caso, terão que se inserir no léxico do trauma e na visão tradicional da ideia de vítima ("vítima de verdade") com capacidade de voz limitada pela vulnerabilidade, dependência, fragilidade e passividade que têm. Por outro lado, serão consideradas como perpetradoras quando isso for ao encontro do interesse dos construtores desse discurso.

\section{Meninas Soldados: uma visão geral}

Esta seção apresenta a discussão sobre meninas soldados no mundo de maneira geral. Os relatórios das organizações internacionais apresentam uma visão mais geral dos casos específicos de países africanos e asiáticos, que foram coletadas pelos autores com o apoio dos escritórios da ONU nos respectivos países. Rachel Brett (2004), como Representante de Direitos Humanos e Refugiados do Quaker UN Office, apresenta uma reflexão do tema das meninas soldados com o uso de relatórios do Alto Comissariado das Nações Unidas para os Direitos Humanos e do UNICEF, elaborando um dos estudos mais completos sobre o tema até então. Em sua pesquisa de 2003 (Brett, 2003a), apresenta essa discussão sobre crianças soldados também com o uso de relatórios internacionais e da legislação sobre o tema. Koffi Annan (2000) apresentou seu relatório ao Conselho de Segurança da ONU quando era então Secretário Geral da Organização. Em 1996, Graça Machel (1996) elaborou um relatório sobre o impacto de conflitos armados sobre crianças, a pedido do Secretário Geral da ONU. Este último é considerado um documento base no estudo de crianças soldados e já traz informações sobre o uso de meninas como combatentes. 
Já os estudos mais específicos foram feitos com metodologias que vão desde análises de casos em Comissões da Verdade até entrevistas e etnografias com ex-meninas soldados. A maior parte dos estudos se concentra em casos africanos, mas isso não significa que se encontrem meninas soldados apenas nesse continente. Como constatou Machel (1996), crianças soldados estão presentes em todos os continentes, menos na Antártica. A pesquisa de Park (2006) analisa como meninas foram consideradas na Comissão da Verdade e Reconciliação de Serra Leoa (Sierra Leone's Truth and Reconciliation Commission) depois do conflito armado interno no país entre 1991-2002. Tanto grupos armados como o exército de Serra Leoa utilizaram meninas e meninos como soldados durante o conflito. Wessells (2007) realizou entrevistas com 40 meninas que foram recrutadas, durante a Guerra Civil em Angola, em Luanda (capital do país) e na província de Huambo. Worthen et alii (2010) utilizaram uma metodologia de ação participativa multianual iniciada em outubro de 2006 com cerca de 30 meninas e jovens mulheres que participaram de conflitos armados e retornaram, com filhos, para as suas comunidades na Libéria, Serra Leoa e no norte de Uganda. Nessa pesquisa, os autores percebem como as meninas sofreram estigmas $e$ não foram inseridas nos discursos de perdão existentes para os meninos e como, por meio de apoio entre os pares e atividades de geração de renda, elas passaram a ser reconhecidas como valorizáveis em suas comunidades. Snodgrass e Obika (2011) realizam um estudo de caso com entrevistas com profissionais de organizações envolvidas na reintegração de crianças soldados em Uganda e também utilizam dados de relatórios de organizações internacionais para discutir a situação das meninas soldados na África.

Meninas sofrem, pelo menos, uma dupla exclusão: primeiro, são marginalizadas por questões de gênero e, segundo, por questões de idade (Park, 2006). Conflitos armados e guerras são entendidos como espaços públicos nos quais o agente característico é um homem adulto (Enloe, 1990), enquanto que meninas, por serem ao mesmo tempo mulheres e crianças, são 
compreendidas como agentes apenas em espaços privados $e$ domésticos. Contudo, meninas soldados não são empregadas apenas para serviços sexuais desempenhados na esfera privada do conflito, mas também atuam como combatentes ativas, revelando publicamente suas faces durante os combates. As meninas são um grupo negligenciado que "desaparece" ou é invisibilizado nas categorias de "crianças" (que não é gênero neutro) ou "mulheres" (que não considera as diferenças de idade, sendo relacionada com adultos do sexo feminino), o que impede que suas necessidades $e$ experiências específicas recebam a devida atenção (Park, 2006). Ao mesmo tempo, a categoria "meninas" não abarca as experiências de meninas indígenas, afrodescentes e que vêm de contextos desfavoráveis. Assim, as garotas não devem ser vistas como meras vítimas - conforme definição de "vítima de verdade" de Lins (2014) - de conflitos armados (Park, 2006), pois, mesmo quando abduzidas, não são passivas. Muitas vezes, elas resistem aos avanços sexuais e sofrem com espancamentos, torturas, estupro $e$ até morte como consequência desse comportamento (Brett, 2004).

Meninas soldados, além de deturparem o conceito tradicional de criança como sujeito que necessita de proteção, também subvertem as noções populares de gênero e feminilidade, pois a guerra é tradicionalmente um domínio masculino. Uma das ditas razões para as meninas serem pouco estudadas é seu menor número em unidades militares se comparado ao de meninos. Porém, em algumas situações, a quantidade de meninas soldados pode chegar a um terço do contingente (Brett, 2004). Wessels (2007) afirma que $40 \%$ dos combatentes em conflitos interestatais contemporâneos são meninas e em algumas áreas elas podem chegar a até metade do grupo armado. Entre 1990 e 2003, meninas eram membros de forçadas armadas em 55 países e participavam de conflitos armados em 38 países. Nos conflitos africanos recentes, elas correspondem a entre $30 \%$ e $40 \%$ de todas as crianças soldados (Park, 2006). Nos conflitos de El Salvador, Etiópia e Uganda, foi reportado que um terço dos menores soldados eram meninas (Annan, 2000). 
O recrutamento de meninas não é acidental ou algo que ocorre em pequena escala, pelo contrário, é uma prática sistemática e difundida (Wessells, 2007). Uma das formas pela qual ela acontece é a abdução ou o sequestro, como relataram as 40 entrevistadas de Wessells (2007). No entanto, muitas meninas juntam-se a grupos armados para fugirem de situações domésticas insuportáveis, nas quais são sujeitas a abusos físicos e sexuais e/ou violência e exploração doméstica, como ocorre na Colômbia, por exemplo (Brett, 2004). Outras se voluntariam porque uma arma pode dar proteção a elas em um contexto de estupros generalizados, tratamentos desumanos, abduções e outras violações de direitos humanos. Há aquelas que realizam um cálculo racional de que é melhor se voluntariarem para escolherem o comandante a que servirão (incluindo serviços sexuais) do que serem abduzidas e estupradas por batalhões inteiros. Dessa forma, o alistamento voluntário de meninas nessa situação é um modo de exercer, em alguma medida, alguma escolha sobre seus parceiros sexuais e isso é mais provável de ocorrer se elas se oferecerem voluntariamente (Brett, 2004). Ao mesmo tempo, muitas vezes essa capacidade de ação das meninas não é reconhecida em processos de DDR (baseados em visões tradicionais de vítimas) ou quando suas comunidades/famílias têm conhecimento dessa realidade; ela é utilizada em discursos discriminatórios que dificultam a reinserção dessas meninas em suas comunidades e para descontruir a imagem delas como "vítimas de verdade" ou meninas, conforme entendido em suas socidades.

Em alguns casos, meninas são mais vulneráveis a abusos sexuais do que mulheres pelo medo que soldados adultos têm de contrair o vírus HIV/AIDS. Assim, eles procurarão meninas cada vez mais novas para serem suas parceiras sexuais, por acreditarem que meninas mais jovens são virgens e menos propícias a estarem infectadas (Park, 2006). Meninas soldados são tomadas como "esposas" de comandantes e usadas como escravas sexuais ou concubinas, mas é interessante observar que meninos soldados também podem sofrer abusos sexuais e há relatos que comprovam 
essa prática. Esses abusos provocam infecções por DSTs $e$ HIV/AIDS, traumas físicos e psicossociais e gravidez indesejada na adolescência, além de estigmatização social (Nwoko, 2011). Além disso, meninas e mulheres afetadas pela guerra sofrem muitos outros riscos de saúde que incluem doenças, mutilação, desnutrição, doenças de pele e respiratórias (Snodgrass; Obika, 2011). Esse grupo ainda é sexualmente explorado, estuprado, abusado de diferentes formas e sujeitado ao tráfico humano, prostituição e casamentos forçados (Nwoko, 2011).

Como já mencionado acima, meninas soldados não ocupam apenas atividades relacionadas ao serviço sexual. Elas desempenham, também, outros papéis baseados em visões tradicionais da divisão do trabalho baseada no gênero, como cozinheiras, enfermeiras, mensageiras e ainda atividades ocupadas pelos meninos, tais como espiãs, carregadoras, recrutadoras de seus pares e combatentes (Brett, 2003a). Assim, não devem ser vistas como meras vítimas (considerando o viés passivo relacionado com a vítima) de eventos intrusivos traumáticos $e$ abusos sexuais, mas são participantes diretas e perpetradoras de atrocidades (Snodgrass; Obika, 2011). Em Serra Leoa, apesar de continuarem a ser os membros menos poderosos de suas unidades armadas, as meninas se sentiam relativamente mais empoderadas do que os civis. Além disso, elas resistiam ativamente à cultura de violência que as rondava por meio de atos de resistência ao falhar intencionalmente em matar alvos durante combate, desenvolver laços de solidariedade entre elas, planejar e executar fugas de seus abdutores e resistir à violência sexual fingindo menstruação (Park, 2006).

Por causa de suas experiências de trabalho doméstico $e$ sexual forçados e suas peculiaridades físicas e sociais, que envolvem mutilações genitais, gravidez, criação e transporte de crianças, meninas requerem atenção especial e não podem ter suas necessidades específicas omitidas no discurso presumidamente gênero-neutro de crianças soldados (Park, 2006). $\mathrm{O}$ processo de gestar uma criança pode trazer riscos físicos para as meninas soldado como problemas ginecológicos por causa de 
complicações e infecções ao dar à luz ao bebê (Park, 2006). Carecendo de habilidades maternais e apoio familiar, sem cuidados pré e pós-natais, algumas meninas induzem abortos por contra própria, rejeitam seus filhos e, em alguns casos, cometem infanticídio (Park, 2006).

Quando retornam para suas famílias e comunidades, meninas que foram sexualmente abusadas e suas crianças são geralmente rejeitadas e sujeitas a estigmas e provocações. É comum essas meninas, vítimas de violência sexual, serem classificadas como "usadas" em discursos machistas de suas comunidades (Park, 2006). Para Brett (2004), meninos soldados seriam inseridos por suas sociedades em uma lógica que normalmente os alivia da culpa por estarem drogados, terem sido coagidos, ou não terem tido escolha. No entanto, mesmo abduzidas, meninas que foram ou acreditam terem sido sexualmente ativas não aparecem nesses discursos de "perdão", visto que a sociedade e suas comunidades locais não parecem observar sua falta de escolha e absolvê-las da culpa. Jovens mulheres e garotas nessa situação são marginalizadas, quando retornam por meio de programas de reintegração ou de maneira independente. Jovens mães são vistas como se tivessem violado as regras de suas comunidades por terem tido filhos fora das normas socialmente aceitas do casamento (Mckay; Mazurana, 2004; Worthen et alii, 2010).

No entanto, poucas meninas são desmobilizadas $e$ reintegradas, em comparação aos meninos (Brett, 2003a). Assim, programas de DDR normalmente ignoram as necessidades desse grupo (Park, 2006). Nesse sentido, todos esses projetos que fazem essa exclusão intencionalmente ou por descuido representam um ato de discriminação de gênero (Brett, 2003a). Programas de DDR são projetados para atender o maior número de crianças desmobilizadas, contudo, como há poucos estudos sobre meninas soldados e nem sempre elas são classificadas como tal, entidades que desenvolvem atividades de DDR não estão sempre preparadas para desmobilizar e reintegrar esse grupo, ainda mais para 
considerar especificidades dentro do grupo das meninas como indígenas ou afrodescendentes.

Para Brett (2004), a maior ironia seria que a discriminação, o tratamento desumano e violência em casa, no conflito e na sociedade, são o que leva as meninas a se tornarem militarmente ativas, porém, tanto no momento do recrutamento, quanto no de desmobilização, os maiores problemas enfrentados por elas são seus papéis desempenhados no conflito $e$ seus status na sociedade. Ou seja, a discriminação por questões de gênero está presente em todas as etapas do processo e contribui para que essas meninas não sejam reconhecidas como "vítimas de verdade" por questões de gênero que envolvem atividades sexuais.

Assim, a não identificação $e$ o não reconhecimento formam um círculo vicioso (Brett, 2004) no qual meninas se alistam para serem reconhecidas e fugirem de situações de discriminação de gênero e depois são discriminadas e marginalizadas exatamente por terem tomado essa decisão. O grau de escolha das meninas também é relativo, mas, aparentemente, suas famílias $e$ sociedades patriarcais parecem não reconhecer a situação que motiva a tomada de decisão dessas meninas ou mesmo o contexto que circunda seu recrutamento forçado, mantendo a culpa da violação das normas e da concepção tradicional de relações familiares exatamente naquelas que mais precisariam de apoio $e$ motivos para retomar suas vidas. A visão de "vítima de verdade" não consegue reconhecer as estratégias de resistência $e$ empoderamento das meninas soldados. Contudo, mesmo em situações em que claramente as meninas não desenvolveram essas estratégias, o padrão de comportamento esperado de uma menina e a questão sexual impedem que as meninas soldados sejam reconhecidas como "vítimas de verdade" e perdoadas. Isso não ocorre com os meninos, que não possuem expectativas relacionadas com castidade e virgindade, por exemplo. 


\section{As meninas colombianas no conflito armado interno}

O tema das crianças soldados na Colômbia não recebe muita atenção nos relatórios oficiais. Nesse sentido, é ainda mais complicado encontrar informações sobre meninas soldados, especialmente dados que contextualizem seu recrutamento, apresentando estratégias de empoderamento e resistência. Neste artigo, optou-se por trabalhar com relatórios e estudos que consideram as meninas soldados sob uma optica além da tradicional (de vítimas de violações sexuais) presente nos relatórios do Conselho de Segurança das Nações Unidas que serão analisados ao final desta seção. Dessa forma, a discussão aqui apresentada é baseada em dados da Human Rights Watch em seu relatório "You'll learn not to cry", de 2003, que contou com entrevistas com 112 ex-crianças soldados na Colômbia; da pesquisa de Natalia Springer (2012) que realizou entrevistas com 491 crianças desvinculadas do conflito armado e 7 recrutadores de diferentes grupos armados, contrastando-as com uma base de dados com informações socioeconômicas de todos os municípios da Colômbia; da USAID e da OIM (2017) sobre a desmobilização de crianças soldados desde 1999. O relatório da Watchlist on Children and Armed Conflict (2004) reúne informações e dados que foram coletados em diversas partes do mundo sobre crianças soldado, incluindo a Colômbia. Esses dados são complementados pela revisão de literatura de Spellings (2008) que compara a situação das meninas soldados na África (Serra Leoa e Norte de Uganda), nas Américas (Colômbia e El Salvador) e no Sul do Pacífico (Filipinas e Sri Lanka).

Todas as partes envolvidas no conflito armado colombiano (forças armadas colombianas, guerrilhas, paramilitares e grupos pós-desmobilização, mais conhecidos como BACRIM) utilizam crianças soldados em alguma capacidade - o exército colombiano apenas para atividades de inteligência e para obter informações via interrogatórios. A Human Rights Watch calculou que existiam entre 11.000 e 14.000 menores combatentes, em 2003, ou seja, um em cada quatro combatentes tinha menos de 18 anos naquele 
ano, quando houve o processo de desmobilização dos paramilitares, reunidos principalmente sob a sigla Autodefensas Unidas de Colombia (AUC). Desse modo, a Colômbia já era o quarto país que mais usava crianças soldados no mundo, perdendo apenas para Myanmar, Libéria e República Democrática do Congo (Watchlist on Children and Armed Conflict, 2004:26). Em 2012, segundo Springer, existiam na Colômbia 18.000 crianças soldados. Isso significa que houve um aumento no número de crianças vinculadas nos últimos anos, apesar dos avanços nas legislações nacional e internacional sobre o tema. Assim, $42 \%$ das Fuerzas Armadas Revolucionais de Colombia-Ejército del Pueblo (FARC-EP), 44\% dos membros do Ejército de Liberación Nacional (ELN), $40 \%$ dos componentes da AUC (que não se extinguiram, mas formaram outros grupos armados) possuem menos de 18 anos. Atualmente, as Bandas Criminales (BACRIM) são os grupos que mais recrutam crianças, de modo que suas forças são compostas por mais de $50 \%$ desse tipo de combatente. Além dessas, outras 100.000 não são crianças soldados, mas realizam trabalho infantil em setores da economia ilegal controlados por grupos armados (principalmente no cultivo e no manuseio da coca). Essas crianças podem acabar envolvidas diretamente nas hostilidades em caso de necessidade de seus recrutadores (Springer, 2012).

$\mathrm{O}$ recrutamento $e$ o uso de crianças soldados pelas guerrilhas (FARC-EP e ELN), paramilitares e grupos armados (BACRIM) é uma política metódica, sistemática e deliberada para controlar populações, territórios e recursos estratégicos, que incide sobre uma população em extrema vulnerabilidade (Springer, 2012). É interessante observar que mais de $80 \%$ das crianças soldados colombianas afirmam que ingressaram em um grupo armado por causas voluntárias. Isso impacta a discussão sobre vítimas de verdade realizada até aqui $e$ a discussão sobre voluntariedade presente na seção anterior. Ainda que a Corte Constitucional Colombiana reconheça as crianças com até 18 anos desmobilizadas como vítimas, as comunidades desses menores 
talvez não tenham a mesma impressão se considerarem que as crianças foram voluntariamente para o conflito armado.

Outro problema dessa situação na Colômbia, é que não há um fim do conflito armado, apenas um acordo de paz com um dos grupos armados. Sendo assim, se não forem considerados os fatores que levaram meninas e meninos a se voluntariarem, é possivel que eles optem por fazer parte de outros grupos armados, se forem colocados na mesma situação. Por fim, jovens com mais de 18 anos que entraram nos grupos armados enquanto crianças não se inserem na definição de vítima da Corte Constitucional. Isso coloca essa população em um limbo e demandará trabalho da Justiça para lidar com essa questão. Por fim, se a definição da Corte Constitucional abarca meninas soldados na teoria, não fica claro nos relatórios analisados se as comunidades (especialmente no caso das meninas indígenas e afro-colombianas) receberam essas meninas de braços abertos como vítimas de um conflito armado.

Essa discussão de crianças soldados como vítimas é ainda mais necessária porque as crianças soldados desempenham no conflito uma série de atividades que pode fazer com que elas sejam classificadas como perpetradoras. As crianças soldados são utilizadas para trabalhos de inteligência (escutar conversas e passar informações, espionar) ou vigilância (ficar de guarda, patrulhar ou cuidar de sequestrados, o que inclui instalar minas antipessoais 92\%); para cultivar, cozinhar e construir fossas (90\%); para combater, assaltar e participar em operações (incluindo atividades de contraguerrilha) (87\%), em comunicações (17\%), em atividades administrativas e de apoio logístico (transporte de documentos, armas, dinheiro) (19\%), em extorsões (50\%), em assassinatos seletivos (ajustes de contas e castigos exemplares) (42\%) e em sequestros (36\%); para tarefas de saúde (14\%) e em disposição e manejo de cadáveres (50\%) (Springer, 2012:45).

Na Colômbia, meninas podem representar entre 25 e $50 \%$ da composição das guerrilhas e dos paramilitares (Spellings, 2008). Algumas foram recrutadas com apenas 8 anos de idade (HRW, 2003). Diferentemente de conflitos africanos, nos quais a abdução 
é a principal forma de alistamento, na Colômbia, a maior parte dessas meninas se voluntaria como um mecanismo de emancipação e empoderamento de uma estrutura social rígida, hierárquica e machista (Springer, 2012; Spellings, 2008). Conforme discutido na seção anterior, muitas delas se voluntariam para acabar com os abusos sexuais, violência e maus tratos que sofrem em casa e para ter acesso a proteção e sobrevivência. Nesse caso, o grupo armado é visto como forma de escapar de um contexto familiar abusivo e desfavorável (Spellings, 2008).

Enquanto, na África, as meninas são recrutadas principalmente para fins sexuais (Spellings, 2008), na Colômbia, elas atuam como combatentes e recebem o mesmo treinamento que os meninos (Spellings, 2008). Elas são treinadas para lutar $e$ armar minas, são ensinadas a lidar com armas, a desempenhar papéis de inteligência $e$ a tomar parte em operações militares (HRW, 2003). Meninas desvinculadas afirmam que a vida na guerrilha é mais igualitária do que no mundo civil (HRW, 2003). Ademais, meninas sentem que estão empoderadas por terem armas em comparação com civis, mesmo sendo o grupo mais desempoderado na hierarquia dos grupos armados colombianos.

Para conseguir informações, essas meninas podem utilizar o apelo sexual, seduzindo pessoas-chave de grupos rivais. Ainda que o estupro seja um ato punível dentro dos grupos armados colombianos, muitas dessas meninas acabam sofrendo violência sexual baseada em gênero, pois ceder às investidas de comandantes pode significar acesso a benefícios, privilégios $e$ proteção (HRW, 2003). Isso faz com que a maior parte delas acabe se envolvendo em algum tipo de relacionamento sexual com homens mais velhos que estão em posições hierárquicas superiores (especialmente comandantes). Por mais que esses relacionamentos não sejam forçados, essas meninas estão em uma situação desfavorável para negarem as investidas e acabam se relacionando com parceiros que podem decidir sobre a vida ou a morte delas (HRW, 2003). Há, também, a prática de dar presentes para as meninas "mais bonitas", comum entre os comandantes. Algumas reportam que recebiam roupa íntima nova, cremes para 
a pele e maquiagens a que não tinham acesso em suas casas (Springer, 2012).

Em grupos paramilitares, é mais comum que meninas sejam vistas como objetos sexuais, até porque são elas que desempenham as funções de limpeza e cozinha (HRW, 2003). Nas guerrilhas, as meninas a partir dos 12 anos são forçadas a utilizarem métodos contraceptivos, tais como a inserção de dispositivos intrauterinos (DIU) e a aplicação de injeções semanais. Além disso, normalmente as meninas que engravidam são forçadas a abortarem (HRW, 2003). Há claramente uma violação dos direitos reprodutivos dessa população (Spellings, 2008).

Assim como os meninos, as meninas não recebem educação formal enquanto estão servindo como combatentes. Isso diminui sua possibilidade de inserção no mercado de trabalho depois que são desmobilizadas (Spellings, 2008). A falta de oportunidades laborais e educacionais aumenta a probabilidade de que essas crianças sejam re-recrutadas por grupos armados (em casos em que não houve de fato o fim do conflito) ou se envolvam com a criminalidade.

Outra discussão envolve a possibilidade de transmissão de uma cultura de violência entre gerações. $\mathrm{Na}$ sociedade colombiana, as mães são as principais responsáveis por transmitir valores para seus filhos (Spellings, 2008). Por causa disso, há uma preocupação de que ex-meninas soldados que por ventura tenham tido filhos durante seu recrutamento possam transmitir valores de violência para essa nova geração. A sociedade colombiana entende que crianças acostumadas com comportamentos de guerra podem ensinar para seus futuros filhos modelos e comportamentos violentos. Isso recai principalmente sobre as meninas.

Uma visão tradicional das meninas soldados como vítimas não consegue reconhecer que o recrutamento pode ser um tipo de empoderamento para elas, que vivem em sociedades patriarcais $e$ machistas convivendo com a violência de um conflito armado que dura mais de 50 anos. Também não consegue reconhecer as escolhas das meninas em se envolverem sexualmente com seus 
comandantes ou o fato de elas considerarem a vida na guerrilha mais igualitária como estratégias de resistência e empoderamento. Visões tradicionais de menina e vítima impedem que seja reconhecido o fato de que meninas ocupam diferentes papéis no conflito armado, não apenas em atividades de cuidado $e$ sexuais que são relacionadas com o gênero feminino, mas também como combatentes, recrutadoras e em serviços de inteligência. Esse reconhecimento da experiência das meninas soldados é fundamental para desenhar programas de DDR que levem em consideração as particularidades desse grupo, principalmente de meninas indígenas e afro-colombianas que são mais afetadas pelo conflito, mas que não aparecem como categorias separadas nos relatórios.

Cumpre notar que há três relatórios específicos sobre crianças e conflitos armados elaborados pelo Representante Especial do Secretário Geral sobre Crianças e Conflitos armados sobre o tema na Colômbia em 2009, 2012 e 2016. Ademais, depois da criação da Missão de verificação do Acordo de Paz da Colômbia em 2016, o Conselho de Segurança passou a publicar relatórios periódicos sobre o país, informando sobre os desenvolvimentos do acordo de paz e a atuação da Missão de Verificação. Esses relatórios possuem uma seção chamada Proteção da Criança (Child Protection) em que há informações sobre a situação das crianças. Nesses documentos, ainda que haja informações sobre desmobilização, não há menção específica sobre a situação das meninas muito menos considerando os marcadores de etnia e raça. Como reconhece a própria ONU e Springer (2012), há maior probabilidade de uma criança indígena ser recrutada porque os recrutadores acreditam que elas são mais resistentes às condições de luta da guerrilha e também desertariam menos. O conflito colombiano afeta desproporcionalmente meninas indígenas e afrodescendentes, porém há pouca menção desses grupos nos relatórios. Isso pode ser decorrente de noções racializadas de vítimas. Esse é um dos outros problemas da categoria de crianças soldados na Colômbia. Ela homogeneiza diferentes experiências no pré, durante e pós-conflito dentro de 
uma mesma definição de vítima que é mobilizada estrategicamente em discursos políticos e humanitários.

O relatório apresentado pelo Secretário Geral da ONU em 26 de agosto de 2009 sobre Crianças e Conflitos Armados na Colômbia reconhece que aquele país não faz parte da agenda do Conselho de Segurança, mas que o governo colombiano aceitou participar do mecanismo de monitoramento e relatoria criado pela Resolução do Conselho de Segurança 1612 (2005). Isso mostra que a Colômbia recebe menos atenção do Conselho de Segurança e da comunidade internacional do que outros países (principalmente africanos e asiáticos) que estão na agenda do Conselho de Segurança. Haveria uma tendência da comunidade internacional em reconhecer as meninas soldados em conflitos que estão na agenda do Conselho como vítimas do conflito armado, em oposição àquelas meninas envolvidas em conflitos que não recebem atenção do órgão. Estas últimas não entrariam nem no imaginário social como meninas soldados. Em 2009, o relatório reconhecia que as FARC-EP continuavam a recrutar crianças incluindo meninas, apesar de terem se comprometido com o Conselho a não mais fazer isso. Também reconhecia a relação entre deslocamento forçado e recrutamento, a maior vulnerabilidade de crianças indígenas e o uso de crianças em atividades de inteligência pelas forças armadas colombianas, assim como a demora dos militares em enviarem crianças apreendidas de grupos armados para programas de reintegração. O relatório apresenta que meninas membros de grupos armados sofrem grave violência sexual, sendo forçadas a manterem relações sexuais com adultos e abortarem caso engravidem. Também reconhece a prática de uso forçado de anticoncepcionais que podem prejudicar a saúde das meninas.

Nota-se que não há muita atenção dada ao tema das meninas soldados com exceção da questão sexual. Isso traduz uma visão específica do ser menina soldado como uma vítima de abuso sexual, sem reconhecer constrangimentos que levam ao seu recrutamento nem estratégias de empoderamento e resistência presentes nos relatórios apresentados anteriormente. 
O relatório de 21 de março de 2012 reconhece que crianças indígenas e afrodescendentes são mais vulneráveis do que outras a graves violações, incluindo o recrutamento. Uma diferença em relação ao relatório anterior é o reconhecimento da existência de um conflito armado pelo governo colombiano em 2011. Esse reconhecimento abre possibilidade para que o tema de crianças soldados no país seja visibilizado. O relatório continua a documentar as mesmas informações presentes no documento anterior: recrutamentos de menores por todas as partes do conflito, incluindo uso de crianças em atividades de inteligência $e$ interrogatórios pelas forças armadas e grave violência sexual com uso de abortos forçados no caso de meninas que fazem parte dos grupos armados. Há uma mesma visão específica de vulnerabilidade, meninas soldados como vítimas de crimes sexuais sem qualquer discussão sobre agência, empoderamento $e$ resistência.

O relatório de 04 de outubro de 2016 traz informações sobre as violações dos direitos da criança que aconteceram na Colômbia entre setembro de 2011 e junho de 2016. O relatório aponta como pontos positivos o acordo assinado com as FARC-EP em maio de 2016 para a liberações de crianças menores de 15 anos de suas fileiras e o acordo de paz aprovado em 2016. O documento afirma que $30 \%$ dos menores separados são meninas e que elas possuem uma idade média de recrutamento de 13,4 anos que é menor do que a idade média de 14,1 anos dos meninos; e reconhece um maior recrutamento de crianças em áreas rurais pelas guerrilhas $e$ em periferias de áreas urbanas e locais estratégicos para o tráfico de drogas por grupos pós-desmobilização.

Ademais, o documento reitera que menores foram utilizados para cometer crimes e cita o exemplo de uma criança de 12 anos, comentando que isso dificulta a reintegração desse menor. Esse ponto é delicado porque o reconhecimento da criança soldado como perpetradora de atrocidades pode abalar a ideia "vítima de verdade" baseada em concepções tradicionais de vulnerabilidade da infância. Ainda assim, não há menção das meninas soldados como perpetradoras, colocando maior atenção na questão da 
violência sexual. O relatório apresenta como uma boa prática o fato de a Corte Constitucional da Colômbia ter garantido que todas as crianças liberadas de qualquer grupo armado não estatal (incluindo os grupos pós-desmobilização) sejam tratadas como vítimas do conflito e tenham direito a programas de $\mathrm{DDR} e$ compensação de acordo com a Lei de Vítimas e Restituição de Terra.

Por um lado, é importante que meninas soldados sejam reconhecidas com vítimas para terem acesso a programas de DDR e compensação e alguma possibilidade de participação dentro da categoria de vítimas. Por outro lado, é importante entender experiências particulares de meninas que se envolveram em diferentes grupos armados e que possuem diferentes marcadores sociais tais como etnia, classe social, local de residência e raça. Essas diferentes experiências do que é ser uma "menina-soldado" precisam ser consideradas para evitar que as meninas sejam recrutadas novamente por grupos que não assinaram acordos de paz com o governo. Por fim, cumpre destacar que o tema de crianças soldados recebe pouca atenção dentro do universo maior de vítimas do conflito armado colombiano. De acordo com dados da USAID e OIM (2017), até o final do mês de setembro de 2017, havia 8435 crianças vítimas de recrutamento forçado registradas na Unidade de Vítimas do governo colombiano. Entre 1999 e setembro de 2017, 6394 crianças (1879 meninas) e 60\% delas exmembros das FARC-EP tinham passado por programas de DDR. Esses são números pequenos dentro do universo de mais de 8,532,636 vítimas registradas desde 2011 na Unidade de Vítimas colombiana, 7,265,072 delas deslocadas de maneira forçada (Amnesty International, 2018). Em meio a todas essas vítimas, é importante entender como o governo colombiano e a sociedade lidarão com vítimas que deturpam a ideia tradicional de vulnerabilidade, ou seja, principalmente meninas que foram combatentes e sexualmente ativas em uma sociedade machista, violenta e hierárquica 


\section{Considerações finais}

A decisão da Corte Constitucional da Colômbia em fevereiro de 2016 garante que todas as crianças, incluindo as meninas soldados, que se desvincularem antes dos 18 anos de idade devem ser reconhecidas como vítimas do conflito armado interno. Reconhecer as meninas soldados colombianas como vítimas significa dar inteligibilidade ao sofrimento por elas vivido em razão do conflito armado interno, não importando se seu recrutamento foi voluntário ou não, e garantir a elas compensação e certa possibilidade de participação no momento pós-acordo e em mecanismos de construção da verdade e da paz. A questão aqui discutida é que o envolvimento de meninas soldados em conflitos armados não necessariamente encaixa na definição de "vítima de verdade" como vulnerável e traumatizada que é utilizada em discursos políticos e humanitários. Ademais, encaixar todas as experiências das meninas soldados em uma "caixinha" baseada principalmente em violência sexual e desempenho de papéis tradicionais de gênero não consegue entender a fundo as diversas experiências dessas meninas, considerando seus diferentes locais de fala e seus marcadores sociais de classe, raça $e$ etnia. Finalmente, visões tradicionais de meninas soldados não conseguem perceber suas estratégias de empoderamento $e$ resistência, mesmo seu recrutamento, em sociedades patriarcais envolvidas em conflitos armados.

Se por um lado as meninas soldados colombianas devem ter seus direitos reconhecidos, tratamento garantido para seus traumas e programas de DDR desenvolvidos pensando em suas necessidades específicas, por outro, elas não são entendidas como "vítimas de verdade" porque, principalmente aquelas que se voluntariam, não preenchem os requisitos de vulnerabilidade, passividade, dependência $e$ fragilidade. Isso porque viver nas guerrilhas e a própria decisão de se juntar a um grupo armado exige muita força $e$ vontade de sobreviver em uma situação de violação de direitos humanos e falta de proteção por parte dos Estados. Essas meninas estavam armadas e eram combatentes, o 
que dificulta ainda mais que elas possam ser identificadas por suas comunidades como vítimas no sentido ideal da palavra. Ademais, o fato de elas terem sido sexualmente ativas de maneiras que não seguiam as regras tradicionais do matrimônio e com pessoas consideradas como o "inimigo" contribui ainda mais para que elas sejam excluídas de discursos de perdão (e mais uma vez da categoria da vítima) em suas comunidades locais, situação essa que não se aplica aos meninos.

As meninas soldados colombianas devem ser classificadas como vítimas do conflito armado interno na Colômbia mesmo que seu recrutamento tenha sido voluntário. Ao mesmo tempo deve ser reconhecida sua $\mathrm{VOz}$, as situações que levaram ao recrutamento e sua atuação não passiva tanto no momento pré, quanto durante e após o recrutamento. Isso será necessário para que as meninas superem seus traumas ao terem sua capacidade de agência reconhecida pela visão de vítima. Sendo assim, aqui o conceito de vítima se refere muito mais ao reconhecimento de uma situação de sofrimento e violência vivenciada por elas do que de uma clara distinção entre agressor/agredido e do fato de elas preencherem os quesitos de passividade, fragilidade, vulnerabilidade e dependência, o que não ocorre na discussão apresentada.

As situações de violência e discriminação de gênero motivam o envolvimento das meninas como soldados no conflito armado interno. Elas continuam vivendo situações de extrema violência e violação de direitos humanos tanto durante seu alistamento como quando saem dos grupos armados e não são inseridas em programas formais de DDR pensados para atender suas necessidades específicas, principalmente meninas indígenas $e$ afro-colombianas que são desproporcionalmente afetadas pelo conflito, se comparadas com outros grupos. Nesse sentido, este trabalho propôs trazer luz para um tema pouco estudado na América Latina. Novos estudos, pesquisas e políticas públicas devem ser desenhados e implementados para entender $e$ atender as necessidades desse grupo duplamente invisibilizado nas categorias de crianças e mulheres e não reconhecidos como 
vítimas que possuem voz para apresentar sua situação. Ademais, maiores pesquisas são necessárias considerando meninas indígenas, afrodescendentes e provenientes de áreas rurais. Suas experiências não são traduzidas em discussões generalizadas sobre meninas soldados. Por fim, talvez fosse interessante pensar na classificação de sobrevivente para as crianças soldados, principalmente as meninas envolvidas com grupos armados. Essas crianças sobreviveram a um conflito armado da melhor maneira que lhes era possivel, o que por vezes significava o seu recrutamento voluntário. Pela categoria de "sobrevivente" seria mais provável o reconhecimento das estratégias de resistência $e$ empoderamento dessas meninas do que pela categoria de "vítimas de verdade" e seu uso nos discursos políticos $e$ humanitários.

\section{Referências bibliográficas}

AMNESTY InternationaL. Colombia 2017/2018. 2018 [https://www.amnesty.org/en/countries/americas/colombia/reportcolombia/ - acesso em 24 mai. 2018].

Annan, Kofi. Child Soldiers - Life on the Front Line. Security Council Report, Secretary-General Kofi Annan, July 26 ${ }^{\text {th }}, 2000$.

BRETT, Rachel. Adolescents volunteering for armed forces or armed groups. International Review of the Red Cross, vol. 85, $\mathrm{n}^{\circ}$ 852, Dec. 2003a, pp.857-866.

BRETT, Rachel. Girl Soldiers: Denial of Rights and Responsibilities. Refugee Survey Quarterly, vol. 23, n 2 2, 2004, pp.30-37.

BOYDEN, Jo. The Moral Development of Child Soldiers: What Do Adults Have to Fear?. Peace and Conflict: Journal of Peace Psychology, vol. $9, \mathrm{n}^{\circ} 4,2003$, pp.343-362.

BURKE, Jason. Ex-child soldier Dominic Ongwen denies war crimes at ICC trial. The Guardian. 06 December 2016 [https://www.theguardian.com/world/2016/dec/06/dominic-ongwenthe-hague-trial-war-crimes-lra-uganda-acesso em $14 \mathrm{dez} .2016]$. 
DUBINSKY, Karen. Children, Ideology, and Iconography: How Babies Rule the World. The Journal of the History of Childhood and Youth, vol. 5, n 1, Winter 2012, pp.5-13.

EnLOE, Cynthia. Bananas, Beaches and Bases: Making Feminist Sense of International Politics. Berkeley, University of California Press, 1990.

FASSIN, Didier; RECHTMAN, Richard. The Empire of Trauma: An Inquiry into the Condition of Victimhood, Princeton, 2009.

FERNANDO, Jude L. Children's Rights: Beyond the Impasse. Annals of the American Academy of Political and Social Science, vol. 575, Children's Rights, May 2001, pp.8-24.

HumAn Rights Watch (HRW). You'll Learn Not to Cry: Child Combatants in Colombia. New York, 2003. ISBN 1564322882.

ICRC. Children associated with armed forces or armed groups: In Brief. September 2013 [https://www.icrc.org/eng/assets/files/other/icrc-0020824.pdf-acesso em $14 \mathrm{dez}$. 2016].

LINS, Beatriz Accioly. A Lei nas entrelinhas. Dissertação (Mestrado em Antropologia Social), USP, São Paulo, 2014.

MACHEL, Graça. The Impact of War in Children. A/51/306. 26 August 1996 [http://www.un.org/ga/search/view_doc.asp?symbol=A/51/306acesso em 22 mai. 2018].

MCKAY, Susan; MAZURANA, Dyan. Where are the Girls? Girls in Fighting Forces in Northern Uganda, Sierra Leone and Mozambique: Their Lives During and After War. Montreal, International Centre for Human Rights and Democratic Development, 2004.

Monforte, Tanya M. Razing Child Soldiers. Alif: Journal of Comparative Poetics, $\mathrm{n}^{\circ}$ 27, Childhood, Creativity and Representation, 2007, pp.169-208.

NwoKO, Kenneth Chukwuemeka. A Bleak Future, a Wasted Generation: Child Soldier in Africa, Issues of Concern. Journal of Sustainable Development in Africa, vol. 13, n 4, 2011, pp.1-17.

PARK, Augustine S. J. "Other Inhumane Acts": Forced Marriage, Girl Soldiers and The Special Court For Sierra Leone. Social \& Legal Studies, vol. 15, n 3 , Sage Publications, 2006, pp.315-337. 
ROSEN, D. Child soldiers, International Humanitarian Law, and the Globalisation of Childhood. American Anthropologist, vol. 109, $\mathrm{n}^{\circ} 2$, 2007, pp.96-3067.

SARTI, Cynthia. A vítima como figura contemporânea. Cadernos $C R H$, vol. 24, n 61, Salvador, abril 2011, pp.51-61.

SNODGRASS, Lyn; OBIKA, Julaina. Reintegrating former child soldiers into their communities in northern Uganda: A case study. Africa in Focus: Governance in the 21st Century, 2011, pp.221-232.

SPELLINGS, Carolyn R. Scratching the Surface: A Comparison of Girl Soldiers from Three Geographic Regions of the World. International Education, vol. 38, n 1, 2008, pp.21-39.

SPRINGER, Natalia. Como Corderos entre Lobos: Del Uso y Reclutamiento de Niñas, Niños y Adolescentes en el Marco del Conflicto Armado y la Criminalidad en Colombia. Bogotá, CODHES, 2012.

VAUTRAVERS, Alexandre J. Why Child Soldiers are such a Complex Issue? Refugee Survey Quarterly, vol. 27, n 4, 2009, pp.96-107.

WATCHLIST on Children and Armed Conflict. Colombia's War on Children. New York, February 2004, pp.1-47.

Wessells, Michael G. The Recruitment and Use of Girls in Armed Forces and Groups in Angola: Implications for Ethical Research and Reintegration, 2007 [http://www.cpcnetwork.org/admin/includes/doc view.php?ID=471 acesso em 10 dez. 2016].

WORTHEN, Miranda et alii. "I Stand Like a Woman": Empowerment and Human Rights in the Context of Community- Based Reintegration of Girl Mothers Formerly Associated with Fighting Forces and Armed Groups. Journal of Human Rights Practice, vol. 2, n 1, 2010, pp.4970.

\section{Fontes}

CONVENÇÃo das Nações Unidas sobre os Direitos da Criança. Adotada pela Assembleia Geral das Nações Unidas em 20 de novembro de 1989 [http://www.unicef.org/brazil/pt/resources_10120.htm-acesso em 14 dez. 2016]. 
CONVENÇÃO de Genebra relativa ao Estatuto dos Refugiados. Adotada em 28 de julho de 1951 pela Conferência das Nações Unidas de Plenipotenciários sobre o Estatuto dos Refugiados e Apátridas. Entrou em vigor em 22 de abril de 1954, de acordo com o artigo 43. Série Tratados da ONU, No 2545, Vol. 189.

CORTE Constitucional. República de Colombia. Sentencia C-069/16, 2016 [http://www.corteconstitucional.gov.co/RELATORIA/2016/C069-16.htm-acesso em $14 \mathrm{dez} .2016]$.

EsTATUTO de Roma do Tribunal Penal Internacional. Adotado em Roma, Itália, pela Conferência Diplomática de Plenipotenciários das Nações Unidas para a Criação de um Tribunal Penal Internacional, em 17 de julho de 1998.

MINISTERIO del Interior/Republica de Colombia. Ley 1448 de 10 junho de 2011

[https://www.centrodememoriahistorica.gov.co/micrositios/caminosPar aLaMemoria/descargables/ley1448.pdf - acesso em 14 dez. 2016].

PROTOCOLO Facultativo à Convenção sobre os Direitos da Criança sobre o Envolvimento de Crianças em Conflitos Armados. Adotado pela Assembleia Geral das Nações Unidas, em 25 de maio de 2000. [http://www.unicef.org/brazil/pt/resources_10124.htm - acesso em 14 dez. 2016].

Unicef. Cape Town Principles and Best Practices. Cape Town, South Africa, 27-30 April, 1997 [http://www.unicef.org/emerg/index_childsoldiers.Html. - acesso em 14 dez. 2016].

UnICEF. The Paris Principles: Principles and Guidelines on Children Associated with Armed Forces or Armed Groups, February 2007 [http://www.unicef.org/emerg/files/ParisPrinciples310107English.pdfacesso em 14 dez. 2016].

USAID; OIM. Colombia. DDR and Child Soldiers Issues, September 2017. [http://www.oim.org.co/sites/default/files/20.DDR\%2BChildren\%C2\% B4s\%20Issues_September\%202017.pdf - acesso em 22 mai. 2018]

UN High Commissioner For Refugees (UNHCR). Handbook and Guidelines on Procedures and Criteria for Determining Refugee Status under the 1951 Convention and the 1967 Protocol Relating to the Status of Refugees, December 2011, HCR/1P/4/ENG/REV. 3, 
[http://www.refworld.org/docid/4f33c8d92.html - acesso em 22 mai. 2018]

UNITED Nations Security Council (UNSC). Report of the SecretaryGeneral on children and armed conflict in Colombia. S/2009/434, 28 August 2009 [http://www.un.org/en/ga/search/view_doc.asp?symbol=S/2009/434 acesso em 24 mai. 2018].

. Report of the Secretary-General on children and armed conflict in Colombia. S/2012/171, 21 March 2012 [http://www.un.org/en/ga/search/view_doc.asp?symbol=S/2012/171 acesso em 24 mai. 2018].

. Report on children and armed conflict in Colombia (September 2011-June 2016). S/2016/837. 4 October 2016 [http://undocs.org/S/2016/837 - acesso em 24 mai. 2018]. 